\title{
REBROTA DE CEPAS DE ÁRVORES ADULTAS DE ACÁCIA-NEGRA (Acacia mearnsii De Wild.) ${ }^{1}$
}

\author{
Norton Borges Júnior², Maisa Pimentel Martins-Corder ${ }^{3}$, Rita de Cássia Sobrosa ${ }^{4}$, Elias Moreira dos \\ Santos 5
}

\begin{abstract}
RESUMO - O rejuvenescimento de árvores que alcançaram a maturidade de acácia-negra (Acacia mearnsii De Wild.) torna-se necessário devido à dificuldade do enraizamento de ramos adultos. Desse modo, o objetivo do presente trabalho foi estudar a influência da altura de cepa no desenvolvimento de brotações e o melhor período para o corte das árvores. Os ensaios foram instalados em um plantio comercial de acácia-negra aos cinco anos de idade, desenvolvendo-se em espaçamentos de 1,0 x 1,30 m. Utilizou-se o delineamento em blocos ao acaso com seis repetições e seis plantas por parcela. Os tratamentos foram constituídos de diferentes alturas de cepa com corte à altura de: (a) $15 \mathrm{~cm}$, (b) $30 \mathrm{~cm}$, (c) $45 \mathrm{~cm}$ e (d) $60 \mathrm{~cm}$. Os ensaios foram instalados no outono (março) e na primavera (setembro). Foram feitas avaliações aos 45, 90 e 150 dias, através da contagem de cepas com brotações e número de brotações por cepa. O corte das árvores na altura de $60 \mathrm{~cm}$ promoveu elevado índice de rebrota, com aproximadamente $90 \%$ das cepas apresentando brotações novas. Na primavera, obteve-se melhor rebrota de árvores adultas de acácia-negra, em comparação com o ensaio do outono. Esses resultados indicaram a influência da altura de cepa e do período do ano na capacidade de rebrota de indivíduos adultos de Acacia mearnsii.
\end{abstract}

Palavras-chave: melhoramento genético, brotações de touças, clonagem.

\section{STUMP REGROWTH FROM MATURE BLACK WATTLE (Acacia mearnsii de Wild.)}

\begin{abstract}
Rejuvenation of mature black wattle (Acacia mearnsii De Wild.) trees is necessary as it is difficult to root from mature branches. Thus the aim of this paper was to determine the influence of stump height on promoting regrowth and the best period for cutting black wattle trees. The assays were installed in a 5 year-old, 1,0 x 1,3 m spacing black wattle plantation. A randomized block design with 6 replications and 6 plants per plot was used. Treatments constituted of various stump heights with cuttings at (a) $15 \mathrm{~cm},(b)$ $30 \mathrm{~cm},(\mathrm{c}) 45 \mathrm{~cm}$, and (d) $60 \mathrm{~cm}$. The assays were installed in the autumn (March) and spring (September). The assessments were carried out in 45, 90 and 150 days, by counting stumps with sprouts and number of sprouts per stump. Tree cutting at $60 \mathrm{~cm}$ promoted a high regrowth rate, with approximately $90 \%$ of the stumps presenting new sprouts. Regrowth of mature black wattle obtained in the spring was better than in the autumn. These results indicated the influence of stump height and the time of the year on the regrowth ability of mature Acacia mearnsii individuals.
\end{abstract}

Key words: genetic development, stump shoots, cloning.

\footnotetext{
${ }^{1}$ Recebido para publicação em 14.9.2003 e aceito para publicação em 10.8.2004.

${ }^{2}$ Aracruz Celulose S.A. E-mail: <nbjunior@ aracruz.com.br>.

${ }^{3}$ Departamento de Ciências Florestais. UFSM. E-mail: <lbfmaisa@ smail.ufsm.br>.

${ }^{4}$ FEPAGRO. E-mail: <ritasobrosa@yahoo.com.br>.

${ }^{5}$ Empresa Seta S.A. E-mail: <elias@ seta-sa.com.br>.
} 
A acácia-negra (Acacia mearnsii De Wild.) é uma árvore nativa da Austrália que possui enorme importância econômica e social no Estado do Rio Grande do Sul (ASSIS et al., 1993). Apesar dessa importância, poucos estudos foram realizados com essa espécie no Brasil. Apenas recentemente, algumas pesquisas vêm sendo realizadas com a acácia-negra e outras espécies com alta produção de tanino (BECK e DUNLOP, 1999).

A falta de técnicas de propagação vegetativa da acácia-negra tem limitado a utilização de vários métodos no melhoramento genético dessa espécie (ASSIS et al., 1993). O emprego de métodos de melhoramento baseados na multiplicação vegetativa, que produzem plantações comerciais com maior crescimento, uniformidade e qualidade (ROCKWOOD e WARRAG, 1994), depende, dentre outros, da capacidade de enraizamento do material a ser clonado, pois estudos indicam que a idade da planta doadora possui papel determinante no que diz respeito à clonagem de espécies arbóreas, em que o processo de maturação da árvore foi relacionado negativamente sobre o potencial de formação de raízes adventícias (HACKETT, 1988; BECK e DUNLOP, 1999).

Partes rejuvenescidads de plantas adultas são importantes para viabilizar a propagação vegetativa da acácia-negra, uma vez que ramos adultos não enraizaram (ASSIS et al., 1993) e o material vegetal juvenil tem maior capacidade de enraizamento (ASSIS e TEIXEIRA, 1998). Diversas práticas silviculturais foram adotadas para obter brotações juvenis de árvores adultas ou promover o rejuvenescimento de tecidos. A rebrota de cepas foi praticada em árvores de Eucalyptus globulus, aos cinco anos de idade, para obtenção de brotações, as quais forneceram gemas para a micropropagação (BENNETT et al., 1994). Através dessa técnica, utilizaram-se estacas oriundas das brotações de cepas de E. tereticornis, aos seis anos de idade, das quais se retiraram gemas para a micropropagação de árvores-elites (JAMBHALE e PATIL, 1996).

Beck et al. (1998) evidenciaram que a prática do corte das árvores e utilização das brotações foi eficiente para o rejuvenescimento do material adulto. Os autores obtiveram a proliferação de gemas em segmentos nodais cultivados in vitro oriundos das brotações de árvores de acácia-negra com quatro, seis e oito anos de idade, cortadas a uma altura de 1,5 m. Desse modo,

R. Árvore, Viçosa-MG, v.28, n.4, p.611-615, 2004 o objetivo do presente trabalho foi estudar a influência da altura de cepa no desenvolvimento de brotações em árvores adultas de Acacia mearnsii para serem utilizadas na clonagem de indivíduos geneticamente superiores, através das técnicas de propagação vegetativa.

Os ensaios foram instalados em um cultivo de acácianegra com cinco anos de idade, situado no município de Minas do Leão, no Estado do Rio Grande do Sul, pertencente à Empresa Seta S.A.

Segundo a classificação de Köeppen, o clima é do tipo Cfa 2, caracterizado como subtropical, e a precipitação média anual varia em torno de $1.800 \mathrm{~mm}$, com temperatura média anual de $18^{\circ} \mathrm{C}$. A altitude é de aproximadamente $100 \mathrm{~m}$, e os solos são profundos, de textura argilosa e relevo ondulado (EMBRAPA, 1973).

O primeiro ensaio foi instalado no início do outono e, o segundo, no início da primavera. Utilizaram-se 144 árvores plantadas em espaçamento de 1,0 x 1,30 m. Deixou-se uma bordadura de 4,0 $\mathrm{m}$ para diminuir o efeito do sombreamento. Usou-se o delineamento em blocos ao acaso, com seis repetições e seis plantas por parcela. Os tratamentos foram diferentes alturas de cepa com corte a: (a) $15 \mathrm{~cm}$, (b) $30 \mathrm{~cm}$, (c) $45 \mathrm{~cm} \mathrm{e} \mathrm{(d)}$ $60 \mathrm{~cm}$. Os cortes foram feitos em cunha.

No primeiro ensaio foram feitas duas avaliações, aos 45 e 150 dias após o corte das árvores, através da contagem de cepas com brotações. No segundo ensaio, as avaliações foram feitas aos 45 e 90 dias após o corte das árvores, através da contagem de cepas com brotações e número de brotações por cepa. Os valores da percentagem de cepas rebrotadas foram transfomados em arco-seno de $(\% / 100)^{1 / 2}$ e os valores de número médio de brotações por cepa, transformados em $(\mathrm{x})^{1 / 2}$ para as análises estatísticas.

No ensaio realizado no início do outono ( $1^{\circ}$ ensaio), a avaliação realizada aos 45 dias da instalação do teste indicou que aproximadamente $70 \%$ das cepas apresentaram brotações novas decorrentes do corte. Conforme mostrado no Quadro 1, observou-se que o corte das árvores na altura de $45 \mathrm{~cm}$ promoveu a maior quantidade de cepas rebrotadas, porém não diferiu significativamente do corte das árvores nas alturas de 60 e $30 \mathrm{~cm}$, pelo teste de Tukey a $5 \%$ de probabilidade.

Aos 150 dias, verificou-se também que o corte das árvores na altura de $45 \mathrm{~cm}$ promoveu os maiores 
índices de cepas com rebrota, não diferindo significativamente do corte das árvores na altura de $60 \mathrm{~cm}$, pelo teste de Tukey a 5\% de probabilidade (Quadro 1). O coeficiente de variação experimental (CV) mostrou-se relativamente baixo e dentro dos padrões de um ensaio em campo. Em média, houve redução na percentagem de cepas rebrotadas da primeira para a segunda avaliação, devido à mortalidade de algumas cepas, que tiveram como principais fatores a ocorrência de geadas e, ou, ataque de formigas-cortadeiras.

No ensaio realizado no início da primavera $\left(2^{\circ}\right.$ ensaio), constatou-se que cerca de $95 \%$ das cepas apresentaram brotações novas nas cepas com 45 e 60 $\mathrm{cm}$ de altura, aos 45 dias. Aos 90 dias, verificou-se que o corte das árvores na altura de 45 e $60 \mathrm{~cm}$ também promoveram os maiores índices de cepas com rebrota, com aproximadamente $90 \%$ das cepas com brotações novas. Estatisticamente, o corte das árvores nas alturas de 30,45 e $60 \mathrm{~cm}$ não diferiu entre si pelo teste de Tukey a $5 \%$ de probabilidade (Figura 1).

Comparando os resultados do primeiro e segundo ensaios, notou-se que houve um aumento de 10,7 pontos percentuais na percentagem de cepas com rebrota, aos 45 dias. Possivelmente, isso ocorreu devido ao período em que foi instalado o segundo experimento, no início da primavera, quando as condições de temperatura e umidade foram mais adequadas ao desenvolvimento das brotações. Beck et al. (2000) verificaram que a rebrota das cepas de acácia-negra foi influenciada por fatores bióticos e abióticos, como temperatura e umidade, observando maior produção de brotações no período como maior intensidade de chuvas.

Quadro 1 - Porcentagem de cepas de Acacia mearnsii De Wild com rebrota, aos 45 e 150 dias após o corte realizado no início do outono

Table 1 - Percentage of Acacia mearnsii De Wild stumps with regrowth, 45 and 150 days after cut performed in the beginning of autumn

\begin{tabular}{lcc}
\hline Tratamentos & $\begin{array}{c}\text { Cepas com } \\
\text { rebrota (\%) } \\
45 \text { dias }\end{array}$ & $\begin{array}{c}\text { Cepas com } \\
\text { rebrota (\%) } \\
150 \text { dias }\end{array}$ \\
\hline Altura de cepa $-15 \mathrm{~cm}$ & $47,2 \mathrm{~b}$ & $27,8 \mathrm{~b}$ \\
Altura de cepa $-30 \mathrm{~cm}$ & $75,0 \mathrm{a}$ & $36,1 \mathrm{~b}$ \\
Altura de cepa $-45 \mathrm{~cm}$ & $88,9 \mathrm{a}$ & $86,1 \mathrm{a}$ \\
Altura de cepa $-60 \mathrm{~cm}$ & $75,0 \mathrm{a}$ & $80,6 \mathrm{a}$ \\
Média & 71,5 & 57,6 \\
CV $(\%)$ & 12,7 & 19,8 \\
\hline
\end{tabular}

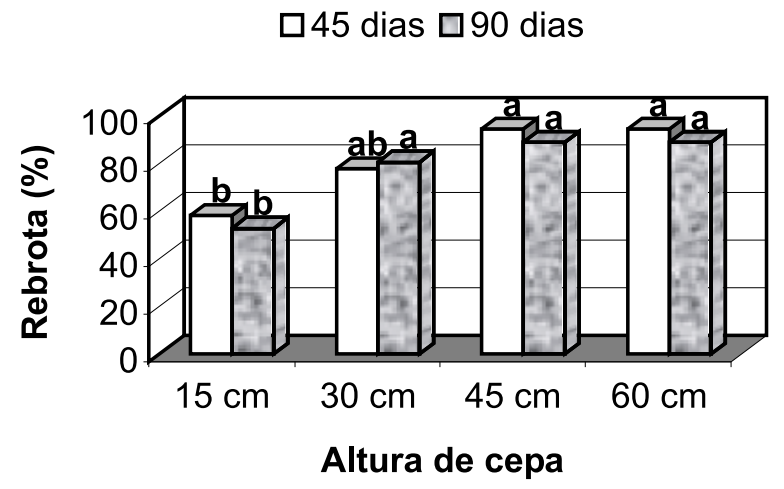

Figura 1 - Porcentagem de cepas de Acacia mearnsii De Wild com rebrota, aos 45 e 90 dias após o corte realizado no início da primavera.

Figure 1 - Percentage of Acacia mearnsii De Wild stumps with regrowth, 45 and 90 days after cut performed in the beginning of spring.

Quanto ao número médio de brotações por cepa, observou-se, nas avaliações realizadas aos 45 e 90 dias, que o corte na altura de $60 \mathrm{~cm}$ promoveu os mais altos valores, porém não diferiu significativamente do corte na altura de $45 \mathrm{~cm}$, pelo teste de Tukey a $5 \%$ de probabilidade (Quadro 2).

Nas avaliações realizadas no segundo ensaio (primavera), tanto na porcentagem de cepas com rebrota quanto no número médio de brotações por cepa, o coeficiente de variação experimental (CV) mostrouse também relativamente baixo e dentro dos padrões de um ensaio em campo (sem condições ambientais controladas). Provavelmente, a variação genética foi reduzida, pois todos os indivíduos são meio-irmãos oriundos da mesma progênie.

Quadro 2 - Número médio de brotações por cepa de Acacia mearnsii De Wild, aos 45 e 90 dias após o corte realizado no início da primavera

Table 2 - Mean number of Acacia mearnsii De Wild sprouts per stump, 45 and 90 days after cut performed in the beginning of spring

\begin{tabular}{lcc}
\hline Tratamentos & $\begin{array}{c}\mathrm{N}^{\circ} \text { médio de } \\
\text { brotações por } \\
\text { cepa aos 45 dias }\end{array}$ & $\begin{array}{c}\mathrm{N}^{\circ} \text { médio de } \\
\text { brotações por } \\
\text { cepa aos 90 dias }\end{array}$ \\
\hline Altura de cepa - $15 \mathrm{~cm}$ & $7,3 \mathrm{c}^{1}$ & $7,8 \mathrm{c}$ \\
Altura de cepa $-30 \mathrm{~cm}$ & $27,2 \mathrm{bc}$ & $24,0 \mathrm{bc}$ \\
Altura de cepa $-45 \mathrm{~cm}$ & $40,7 \mathrm{ab}$ & $35,0 \mathrm{ab}$ \\
Altura de cepa $-60 \mathrm{~cm}$ & $53,3 \mathrm{a}$ & $51,0 \mathrm{a}$ \\
Média & 32,1 & 29,4 \\
CV $(\%)$ & 19,5 & 17,3 \\
\hline
\end{tabular}

R. Árvore, Viçosa-MG, v.28, n.4, p.611-615, 2004 
Houve uma redução de 13,4 pontos porcentuais na porcentagem de cepas com rebrota, da primeira avaliação, aos 45 dias, na segunda avaliação. Constatou-se, também, uma diminuição no número médio de rebrotas por cepa (Quadro 2). Isso aconteceu devido à ocorrência de chuvas de granizo que danificaram as brotações e, ou, ao ataque de formigas-cortadeiras nas novas brotações.

Pelos resultados expostos, o corte das árvores na altura de $60 \mathrm{~cm}$ destacou-se dos demais tratamentos. Apesar de o corte das árvores na altura de $45 \mathrm{~cm}$ ter demonstrado maior capacidade de rebrota no primeiro ensaio (outono), no segundo (primavera) essa tendência não se repetiu, e o corte das árvores nas alturas de 45 e $60 \mathrm{~cm}$ indicou igual capacidade de rebrota. Entretanto, o corte na altura de $60 \mathrm{~cm}$ proporcionou maior número de brotações por cepa, o que significa acréscimo na produção de mudas e maiores possibilidades de sucesso no resgate do material genético selecionado em campo.

A rebrota de árvores que alcançaram a maturidade permite o uso desse material genético rejuvenescido na propagação massal através das técnicas de multiplicação vegetativa, como a micropropagação. O uso de tecidos adultos dificulta a esterilização e, dessa forma, reduz as chances de sucesso do cultivo in vitro, além de apresentar-se recalcitrante à proliferação de gemas axilares e à formação de raízes adventícias (JONES et al., 1990; BECK e DUNLOP, 1999). A utilização de explantes oriundos de brotações de cepas de Eucalyptus radiata ssp. radiata obteve um porcentual de $90 \%$ de enraizamento, sendo bastante superior ao índice de $35 \%$ no enraizamento de explantes de ramos adultos (CHANG et al., 1992). No caso da acácia-negra, o emprego de brotações foi eficiente no rejuvenescimento do material adulto, obtendo-se a proliferação de gemas em $22 \%$ dos segmentos nodais cultivados in vitro oriundos da rebrota das cepas (BECK e DUNLOP, 1999).

Embora a utilização de estacas oriundas de brotações de cepas, em árvores que atingiram a maturidade de Acacia mangium, tenha alcançado pequenas taxas de enraizamento (20\%) em comparação com estacas oriundas de mudas (POUPARD et al., 1994), o emprego de estacas de A. mearnsii obtidas da rebrota de indivíduos adultos apresentaram índices variáveis, chegando a $64 \%$ de enraizamento (BORGES e MARTINS-CORDER, 2002).

R. Árvore, Viçosa-MG, v.28, n.4, p.611-615, 2004
Os resultados indicaram a influência do tamanho da cepa e da época do ano na formação de brotações rejuvenescidas e revelaram o potencial de rebrota de árvores adultas de acácia-negra após o corte. $O$ corte das árvores na altura de $60 \mathrm{~cm}$ foi o tratamento mais promissor, aliando elevado índice de rebrota e maior quantidade de brotações por cepa. O melhor período para o corte e rebrota foi a primavera. Devido à necessidade de estabelecimento de programas clonais, os resultados são particularmente importantes à medida que a técnica pode ser aplicada nos futuros projetos de melhoramento da espécie.

\section{REFERÊNCIAS BIBLIOGRÁFICAS}

ASSIS, T.F. et al. Propagação vegetativa da Acacia mearnsii De Wild.. In: CONGRESSO FLORESTAL PANAMERICANO, 7; CONGRESSO FLORESTAL

BRASILEIRO, 1., 1993, Curitiba. Anais... Curitiba: SBS/SBEF, 1993. p. 150-152.

ASSIS, T.F.; TEIXEIRA, S.L. Enraizamento de espécies lenhosas. In: TORRES, A.C.; CALDAS, L.S.; BUSO, J.A. (Eds.) Cultura de tecidos e transformação genética de plantas. Brasília: Embrapa - SPI/Embrapa - CNPH, 1998. v.1.p. 261-286.

\section{BECK, S.L.; DUNLOP, R. Vegetative} propagation of the black wattle (Acacia mearnsii De Wild.). South Africa: Institute For Commercial Forestry Research, 1999. 15 p. (Bulletin Series, 08/99).

BECK, S.L.; DUNLOP, R.; van STADEN, J. Rejuvenation and micropropagation of adult Acacia mearnsii using coppice material. Plant Growth Regulation, v. 26, p. 149-153, 1998.

BECK, S.L.; DUNLOP, R.; van STADEN, J. Meristem culture of Acacia mearnsii. Plant Growth Regulation, v. 32, p. 49-58, 2000.

BENNETT, I. J. et al. Alternating cytokinins in multiplication media stimulates in vitro shoot growth and rooting of Eucalyptus globulus Labill. Annals of Botany Company, v. 74, n.1, p. 53-58, 1994.

BORGES, N.J.; MARTINS-CORDER, M.P. Efeito de ácido indol butírico no enraizamento de estacas de acácia-negra (Acacia mearnsii De Wild.) Revista Árvore, v. 26, p. 223-227, 2002. 
CHANG, S.H.; DONALD, D.G.M.; JACOBS, G. Micropropagation of Eucalyptus radiata ssp. radiata using explants from mature and coppice material. South African Forestry Journal, v. 162, p. 43-47, 1992.

EMPRESA BRASILEIRA DE PESQUISA AGROPECUÁRIA - EMBRAPA. Levantamento de Reconhecimento dos Solos do Estado do Rio Grande do Sul. Recife: 1973 (Boletim Técnico, 30).

HACKETT, W.P. Donor plant maturation and adventitious root formation. In: DAVIS, T.D.; HAISSIG, B.E.; SANKHLA, N. (Eds.)

Adventitious root formation in cuttings. Portland: Dioscorides Press. 1988. v. 2, p. 11-28.
JAMBHALE, N.D.; PATIL, S.C. Micropropagation of elite Eucalyptus types through shoot tip culture. Indian Forester, v.1, p. 61-64, 1996.

JONES, T.C.; BATCHELOR, C.A.; HARRIS, P.J.C. In Vitro Culture and Propagation of Acacia Species (A. Bivenosa, A. Holosericea, A. Salicina, A. Saligna, and A. Sclerosperma). The International Tree Crops Journal, v. 6, n. 2/3, p. 183-192, 1990.

POUPARD, C.; CHAUVIEERE, M.; MONTEUUIS, O. Rooting Acacia mangium Cuttings: Effects of Age, Within-Shoot Position and Auxin Treatment. Silvae Genetica, v. 43, n. 4, p. 226-231, 1994.

ROCKWOOD, D. L.; WARRAG, E.I. Field performance of micropropagated, macropropagated, and seed-derived propagules of three Eucalyptus grandis ortets. Plant Cell Reports, v. 13, p. 628-631, 1994. 